\title{
O bem jurídico tutelado primariamente pelo crime de descumprimento de medida protetiva e suas implicações
}

A lei Maria da Penha trouxe inúmeras inovações legais que buscam prevenir e reprimir condutas de violência, dentro do contexto doméstico e familiar, violência essa que, antes da promulgação da lei, dificilmente chegava à análise do judiciário. Além dos crimes já tipificados, a lei visa prevenir ainda condutas de violência que não houvessem tipificação expressa, bem como evitar a prática de novos delitos nas mesmas vítimas, por meio da concessão de Medidas Protetivas de Urgência. No entanto, apenas a concessão dessas se mostrou insuficiente, fazendo-se necessário transformar em crime a conduta do descumprimento dessas medidas. Em que pese este dispositivo legal, trazer maior efetividade as medidas protetivas e por consequência diminuir a prática delitiva, existem dúvidas quanto a sua sistemática, que acabam resultando em argumentos que buscam caracterizar a atipicidade do fato, em alguns casos concretos, como a aplicação do princípio da consunção desse delito por outro mais gravoso, e a alegação de consentimento da vítima quanto ao descumprimento. Visando analisar o cabimento destes argumentos frente ao crime previsto, faz-se necessário realizar uma análise sistemática deste tipo penal, com base em uma revisão bibliográfica, por meio do viés metodológico dialético, para entender os reais objetivos da tipificação do crime de descumprimento de medida protetiva de urgência.

Palavras-chave: Descumprimento de medida protetiva de urgência; Princípio da consunção; Lei Maria da Penha; Consentimento da vítima.

\section{The legal good protected primarily by the crime of non-compliance with a protective measure and its implications}

The Maria da Penha law brought numerous legal innovations that seek to prevent and repress conducts of violence, within the domestic and family context, which violence, before the enactment of the law, hardly reached the analysis of the judiciary. In addition to the crimes already typified, the law also aims to prevent conduct of violence, which had no express classification, as well as to prevent the practice of new crimes in the same victims, by granting Urgent Protective Measures. However, only the granting of these proved to be insufficient, making it necessary to make the conduct of noncompliance with these measures a crime. In spite of this legal provision, bringing more effective protective measures and consequently reducing the criminal practice, there are doubts as to its systematic which end up resulting in arguments that seek to characterize the atypicality of the fact, in some concrete cases, such as the application of the law. Principle of the consumption of this crime by another more serious, and the allegation of the victim's consent regarding the non-compliance. In order to analyze the appropriateness of these arguments in relation to the predicted crime, it is necessary to carry out a systematic analysis of this penal type, based on a bibliographic review, through the dialectical methodological bias, to understand the real objectives of the typification of the crime of non-compliance with measure emergency protection.

Keywords: Noncompliance with an emergency protective measure; Principle of consumption; Maria da Penha Law; Victim's consent.

Topic: Direito Penal e Processo Penal

Reviewed anonymously in the process of blind peer

Dayvid Silva Monteiro (10)

Faculdade Independente do Nordeste, Brasil

http://lattes.cnpq.br/6086345158132909

http://orcid.org/0000-0003-3985-9309

dayvidmonteiro10@gmail.com

Isadora Cardoso Aragão

Faculdade Independente do Nordeste, Brasil

http://lattes.cnpq.br/6866597015940273

http://orcid.org/0000-0002-0977-3267

isadoracardoso015@gmail.com

Paulo Cezar Lessa Motta Junior

Faculdade Independente do Nordeste, Brasil

http://lattes.cnpq.br/3829190426060905

http://orcid.org/0000-0002-3121-4728

paullolessajr@hotmail.com

d.

DOI: 10.6008/CBPC2674-6387.2020.002.0001
Received: 16/06/2020

Approved: 10/09/2020
Referencing this:

MONTEIRO, D. S.; ARAGÃO, I. C.; MOTTA JUNIOR, P. C. L.. O bem jurídico tutelado primariamente pelo crime de descumprimento de medida protetiva e suas implicações. Justitia Liber, v.2, n.2, p.1-7, 2020. DOI: http://doi.org/10.6008/CBPC2674-6387.2020.002.0001 


\section{INTRODUÇÃO}

Antes da criação da Lei 11.340/2006, a violência doméstica não era tipificada como crime, havendo apenas uma punição mais severa, quando o crime de lesão corporal fosse cometido no âmbito das relações domésticas, (CP, art. 129 §9ㅇ), e uma agravante de pena, prevista no art. 61, II, alínea "f" do CP. Dessa forma, em que pese a cultura machista impregnada na sociedade, que antigamente, e até mesmo em alguns núcleos atualmente, tendem a normalizar práticas de violência contra a mulher, em razão do arcaico pensamento que trata a mulher como uma propriedade (DIAS, 2010).

Embora a luta das mulheres em busca da igualdade de gênero tenha se estendido por vários anos, a criação de mecanismos que visassem coibir este tipo de violência em específico demorou muito, sendo editada a lei 11.340, que passou a viger apenas em agosto de 2006, há apenas 14 anos (BRASIL, 2006).

Ademais, é valido ressaltar, que a criação dessa lei foi fruto de muita luta, e muita persistência, para que o Direito Penal Brasileiro olhasse para as mulheres em estado de vulnerabilidade, a fim de proteger sua integridade física, psíquica e moral.

A referida lei, recebeu o nome de Maria da Penha, em homenagem a Maria da Penha Maia Fernandes, mulher que foi vítima de violência doméstica, vindo inclusive a ficar paraplégica. Após os episódios violentos em 1984, Maria da Penha começou sua busca incessante por justiça, tendo seu marido e algoz, sido condenado a 15 anos de prisão, 07 anos após o ocorrido, vindo o julgamento a ser anulado, após um recurso da defesa (COELHO, 2010).

Foi realizado novo julgamento em 1996, onde o ex-marido de Maria da penha foi condenado a 10 anos de prisão, tendo cumprido apenas 02 anos em regime fechado. Diante o sentimento de impunidade, ela realizou uma denúncia formal à Comissão Interamericana de Direitos Humanos da Organização dos Estados Americanos (OEA), juntamente com Centro pela Justiça pelo Direito Internacional (CEJIL) e o Comitê Latino-Americano de Defesa dos Direitos da Mulher (CLADEM), dando ao caso uma repercussão internacional, que refletiu na edição da lei 11.340/2006, que hoje se conhece por Lei Maria da Penha (COELHO, 2010).

Uma das inovações trazidas pela lei, foi a concessão de Medidas Protetivas de Urgência. Quando a ofendida é ouvida perante a autoridade policial, deve ser cientificada da existência legal das medidas protetivas, manifestando assim, a vontade ou não de requerê-las ao juiz, ocasião em que a palavra dessa, possui especial valor probatório, em razão da urgência em sua proteção, e a dificuldade de produção de outras provas imediatas. No entanto, as Medidas Protetivas não são definitivas, permanecendo apenas enquanto durar a situação de risco, e podendo inclusive, serem refutadas ao longo da investigação criminal (CARVALHO, 2009).

No entanto, este mecanismo criado, não apresentava a eficácia esperada, vez que não havia consequências bem definidas para seu descumprimento, até que, em 2011, foi inserido na lei, o art. 24-A, que tipificava como crime o descumprimento das medidas protetivas. 
Embora esse tipo penal tenha trago maior efetividade para as Medidas Protetivas de Urgência, os advogados, na defesa de seus clientes tem utilizado de formas de inaplicabilidade desse dispositivo, argumentando pincipalmente, a consunção do crime de descumprimento de medida protetiva, por crime mais gravoso que venha a ser cometido, e por muitas vezes, sustentando o consentimento da vítima, quanto ao descumprimento das medidas.

Ambos os entendimentos implicam na inaplicabilidade do dispositivo em legal em muitas situações de fato, e o objetivo do presente trabalho é analisar, se os argumentos comumente utilizados pelos advogados realmente se aplicam ao crime previsto no art.24-A da lei 11.3340/2006, a partir de um estudo sobre este dispositivo legal.

Este estudo se faz necessário, pois as medidas protetivas de urgência foram criadas justamente para evitar a prática de novos crimes, mas caso o seu descumprimento não traga qualquer punição ao agente, como sustentam comumente os advogados, as próprias medidas protetivas perderiam sua eficácia.

Dessa forma é preciso entender qual o bem jurídico que se pretende defender com a penalização do descumprimento de medida protetiva, e se o dispositivo legal, em sua essência, permite a utilização do instituto da consunção, bem como a revogação tácita das medidas protetivas por meio da mera vontade da vítima.

\section{METODOLOGIA}

A referida investigação temática tem como técnicas a análise bibliográfica, principalmente da própria lei em comento (Lei Maria da Penha, 11.340/2006), bem como de doutrinas e textos sobre o tema, a fim de sistematizar o crime de descumprimento de medidas protetivas, entendendo sua essência. Para tanto, foi utilizado o viés metodológico dialético, colocando diferentes teses e argumentos sobre o tema, em enfrentamento, buscando se chegar ao conceito que melhor se adeque à realidade jurídica atual.

\section{DISCUSSÃO TEÓRICA}

De início, antes de se analisar especificadamente o crime de descumprimento de medida protetiva, é importante ressaltar que o conceito de violência doméstica trazida pela lei, não corresponde a nenhum tipo penal específico, sendo este conceito muito mais abrangente, conforme preceitua o art. 5o da lei 11.3340: "qualquer ação ou omissão baseada no gênero que lhe cause morte, lesão, sofrimento físico, sexual ou psicológico e dano moral ou patrimonial". Descrevendo logo em seguida, de forma exemplificativa, quais são as condutas que se enquadram nesse conceito (DIAS, 2008).

Dessa explanação é possível inferir que a referida lei busca proteger a mulher de todo e qualquer tipo de violência, e não apenas as formas tipificadas como crime pelo Código Penal. Ademais, para que as condutas se caracterizem violência doméstica, é necessário que a ação seja cometida no âmbito da unidade doméstica ou familiar ou em qualquer relação íntima de afeto, independentemente do sexo do sujeito ativo (DIAS, 2008). 
Isso quer dizer que, nem toda ação considerada violência doméstica pela lei, resultará numa ação penal, visto que nem todas as condutas configuram crime. Tal ponto é de suam importância, pois a concessão de Medidas Protetivas de Urgência, não está vinculada à prática de crime, e mesmo que a autoridade policial não realize investigação criminal para apuração delitiva, deve desde logo encaminhar ao juiz, o requerimento de medidas protetivas, o que demonstra um alcance e efetividade maior da Lei Maria da Penha, na proteção da mulher (DIAS, 2008).

Atualmente, após a inclusão de dois novos incisos pela lei 13.984/2020, o art. 22 da Lei Maria da Penha prevê as seguintes Medidas Protetivas de Urgência:

Art. 22. Constatada a prática de violência doméstica e familiar contra a mulher, nos termos desta Lei, o juiz poderá aplicar, de imediato, ao agressor, em conjunto ou separadamente, as seguintes medidas protetivas de urgência, entre outras:

I - suspensão da posse ou restrição do porte de armas, com comunicação ao órgão competente, nos termos da Lei no 10.826, de 22 de dezembro de 2003;

II - afastamento do lar, domicílio ou local de convivência com a ofendida;

III - proibição de determinadas condutas, entre as quais:

a) aproximação da ofendida, de seus familiares e das testemunhas, fixando o limite mínimo de distância entre estes e o agressor;

b) contato com a ofendida, seus familiares e testemunhas por qualquer meio de comunicação;

c) frequentação de determinados lugares a fim de preservar a integridade física e psicológica da ofendida;

IV - restrição ou suspensão de visitas aos dependentes menores, ouvida a equipe de atendimento multidisciplinar ou serviço similar;

$\mathrm{V}$ - prestação de alimentos provisionais ou provisórios;

$\mathrm{VI}$ - comparecimento do agressor a programas de recuperação e reeducação; e

$\mathrm{VII}$ - acompanhamento psicossocial do agressor, por meio de atendimento individual e/ou em grupo de apoio. (BRASIL, 2006)

É importante ressaltar, que antes da Lei Maria da Penha, a violência doméstica era o crime oculto de maior incidência no Brasil, tendo em vista a negligência jurisdicional nestes casos, bem como a ausência de efetiva resposta do Estado aos agressores. Dessa forma, tendo em vista que a lei criou mecanismos processuais mais rígidos para guiar o processo criminal, a imposição de Medidas Protetivas de Urgência não foi suficiente para evitar a prática de violência que não se enquadrasse nos crimes já tipificados. Isto por que, ainda que cientificado da existência da determinação judicial, o agressor continuava a descumprir as medidas, e o pior, sem qualquer consequência legal (DIAS, 2008).

Até o ano de 2018, a única consequência que o descumprimento de Medida Protetiva de Urgência acarretava, era a possibilidade de decretação da prisão preventiva do agressor, prevista no inc. IV do art. 313, do Código de Processo Penal. No entanto, fundamentar a prisão preventiva do indivíduo na inobservância das regras determinadas em medidas protetivas, não era prática comum nos processos do gênero (CARVALHO, 2009).

Ademais, a inserção do art. 24-A, que prevê uma pena de 03 (três) meses a 02 (dois) anos para quem descumpra as Medidas Protetivas de Urgência impostas, também resolveu o conflito jurisprudencial que 
existia, pois, alguns tribunais decidiam pela atipicidade da conduta, enquanto outros sustentavam que $o$ descumprimento se caracterizava crime de desobediência (LIMA, 2019).

Além de garantir maior segurança a vítima, que antes, para noticiar o descumprimento precisava procurar a Defensoria, ou o Ministério Público, após a tipificação desse crime, a própria polícia militar possui competência para instaurar o inquérito, e ainda, em situações de flagrante delito, poderia haver atuação da polícia (LIMA, 2019).

Tal mudança foi de sua importância na prevenção dos delitos, pois antes, para que a Polícia Militar pudesse agir, não bastava o gritante descumprimento, mas era necessário que o agente agredisse a vítima, com alguma conduta tipificada.

Após o tipo pena resolver as dúvidas existentes quanto a conduta de descumprir medidas protetivas de urgência, surge a necessidade de análise do tipo penal para delimitar seu âmbito de aplicação, bem como as causas que gerariam a inaplicabilidade do dispositivo.

Pela simples análise exegética do dispositivo, extrai-se que seu verbo núcleo é "descumprir", desobedecer. A conduta se refere à não observância de uma decisão judicial, emanada por magistrado, ao deferir medidas protetivas de urgência em favor de uma vítima. Ou seja, o bem jurídico que se pretende proteger primeiro, com a tipificação dessa conduta, é a dignidade da justiça, impondo pena a quem descumpra uma decisão judicial (BRASIL, 2006).

Ressalta-se que uma determinação judicial é imperativa, não sugestiva, e seu cumprimento é obrigatório. Dessa forma, caso a integridade da justiça fosse respeitada como deveria, o crime de descumprimento de medida protetiva seria desnecessário. Ao contrário, a mera imposição das MPUs, não estavam sendo suficientes para salvaguardar a integridade física, psíquica e moral das vítimas, vez que os agressores descumpriam essa determinação legal por diversas vezes, dando ensejo a criação deste tipo penal (LIMA, 2019).

Observa-se que, o instrumento que tem por objetivo proteger a integridade física, psíquica e moral da vítima é a própria medida protetiva de urgência, deferida por meio de decisão judicial, enquanto o crime previsto no art. 24-A da lei, visa proteger a imperatividade da determinação judicial.

Por isso, muito embora, a conduta de descumprimento de medida protetiva possa se caracterizar como meio para cometimento de outro crime mais gravoso contra a vítima, os bens jurídicos em defesa são distintos, sendo necessário a punição do agente pela violência causada contra a vítima, bem como pelo fato de ter desrespeitado uma ordem judicial.

Dessa forma, a inaplicabilidade do princípio da consunção ao crime previsto no art. 24-A da Lei 11.340/2006 se dá, visando proteger a imperatividade da decisão judicial que decretou as medidas protetivas, caso contrário, a determinação feita pelo magistrado não traria obrigatoriedade em seu conteúdo, vez que seu descumprimento não acarretaria consequência alguma.

De maneira parecida, é a solução que se dá ao argumento comumente usados por advogados, na defesa de seus clientes, quando do cometimento do crime de descumprimento de medida protetiva. É alegado muitas vezes, que o a aproximação do réu acima da distância permitida, bem como fato de manter 
contato com a vítima, ocorreu por consentimento desta. Assim, se as medidas têm objetivo de proteger a vítima, e a mesma entende por sua desnecessidade, autorizando a aproximação do agressor, tal conduta não deveria ser considerada como crime (CARVALHO, 2009).

Quanto a este ponto, ressalta-se novamente a importância de imposição das medidas protetivas, que é feita por meio de decisão judicial fundamentada, e só pode ser revogada por veículo de igual importância. Como pode a palavra da vítima ser capaz de revogar decisão judicial?.

Conforme já explicitado, o crime de descumprimento de medida protetiva tem por objetivo garantir o cumprimento da decisão judicial, estando muito além da mera vontade da vítima.

As medidas protetivas não possuem caráter perpétuo. Havendo mudança de fato, onde os motivos ensejadores da concessão das medidas deixam de existir, essas podem e devem desde logo serem revogadas, mediante solicitação ao juízo competente, e apenas após nova decisão do magistrado, caso contrário, as partes envolvidas estariam colocando sua vontade acima das decisões do judiciário.

\section{CONCLUSÕES}

Ante o exposto, é nítido os avanços tragos pela Lei Maria da Penha (11.340/2006), quanto a proteção da integridade física, psíquica e moral das mulheres vítimas de violência doméstica e familiar. Neste panorama, merece destaque as Medidas Protegidas de Urgência, que podem ser deferidas em favor da vítima, que incluem proibição de contato, proibição de aproximação em uma distância predefinida, dentre outras de cunho cível, como afastamento do lar, restrição ou suspenção na visitação de dependentes menores e prestação de alimentos provisórios.

Tendo em vista que as medidas se tornaram insuficientes para proteger a vítima, pelo fato de que os agressores comumente desrespeitavam a decisão judicial que as impôs, sem muitas consequências, em 2018, houve uma mudança legislativa que incluiu na Lei Maria da Penha, o art. 24-A, que tipifica como crime, a conduta de descumprir medidas protetivas de urgência.

Esse dispositivo legal trouxe várias implicações positivas, pois não precisa que o agente cometa outro crime que efetivamente cause danos à vítima para que incorra em crime, e dessa forma, evita-se a prática de outros delitos mais graves. Além do mais, o dispositivo permite que a Polícia Militar, diante o descumprimento em flagrante delito, aja imediatamente, procedendo a prisão do agente.

Ademais, partindo da análise do dispositivo citado, bem como no procedimento para deferimento das medidas protetivas de urgência, tem-se que essas visam proteger a integridade física, psíquica e moral da vítima, evitando assim a prática de novos crimes em contexto de violência doméstica, enquanto o crime de descumprimento, protege especificadamente a imperatividade da decisão proferida por magistrado, punindo aquele que ignore ou negligencie determinação judicial.

Dessa forma, quando analisado a aplicação do princípio da consunção do crime de descumprimento, quanto caracterizado como meio para cometimento de outro delito mais grave, pela natureza do dispositivo penal, tem-se que a impossibilidade da aplicação do instituto, uma vez que se trata de crimes que protegem bens jurídicos distintos. 
Caso fosse aplicado o princípio da consunção, o descumprimento da decisão judicial que defere as medidas protetivas, não acarretaria consequência alguma ao agente, e a decisão do magistrado perderia sua eficácia.

Ainda pela análise do art. 24-A da Lei Maria da Penha, cabe ressaltar que muitas vezes, a vítima, beneficiária de medidas protetivas, provoca o descumprimento, entrando em contato com o agressor, seja para tratar de assuntos como divórcio, pensão alimentícia ou guarda, ou mesmo pelo fato de não se sentir mais ameaçada pelo referido.

No entanto, sendo o agressor intimado da existência das medidas protetivas, deve desde logo recusar o contato com a vítima, e evitar, sob qualquer circunstância as descumprir, pois, ainda que a vítima tenha consentido, o agressor deve responder pelo crime.

Isto porque, caso a vítima não tenha mais interesse na vigência das medidas protetivas, ou mesmo o agressor, por não mais subsistirem as razões que deram ensejo à concessão das medidas inicialmente, deve requer, e demonstrar essa condição ao juízo competente, para que as medidas protetivas sejam revogadas.

Caso não fosse este o procedimento, e consentimento da vítima implicasse na atipicidade do fato, a mera vontade da beneficiária das medidas protetivas estaria revogando a decisão judicial que as concedeu. Não é possível que uma decisão judicial seja maculada por tamanho demérito, ainda mais havendo procedimento específico para revogação das medidas protetivas.

Por fim observa-se que, para que o crime de descumprimento de medida protetiva de urgência produza seus plenos efeitos, é necessário ter por base esta análise, de que qual é o bem jurídico protegido por este primariamente, para evitar a decisão pela atipicidade em casos que este instituto não deveria se aplicar.

\section{REFERÊNCIAS}

BRASIL. Lei Maria da Penha: Lei no 11.340, de 7 de agosto de 2006. Dispõe sobre mecanismos para coibir a violência doméstica e familiar contra a mulher. Brasília: DOU, 2006.

CARVALHO, T. A. R.. Violência doméstica e familiar contra a mulher: considerações sobre a efetividade das medidas protetivas e a vedação à aplicação da Lei 0.099/95. 2009.

COELHO, M. A.. Breves considerações sobre a Lei $n$ ㅇ. 11.340/2006: a razão de ser conhecida como 'Lei Maria da Penha'; a inconstitucionalidade de gênero; medidas protetivas; e a existência de crimes de ação penal pública condicionada. 2010

DIAS, M. B.. A Lei Maria da Penha na Justiça: a efetividade da Lei 11.340/2006 de combate à violência doméstica e familiar contra a mulher. 2 ed. São Paulo: Revista dos Tribunais, 2010.

DIAS, M. B.. A Lei Maria da Penha na Justiça. 2008.

LIMA, S. M. M.. O crime de descumprimento de medida protetiva de urgência e suas implicações jurídicas. 2019.

A CBPC - Companhia Brasileira de Produção Científica (CNPJ: 11.221.422/0001-03) detém os direitos materiais desta publicação. Os direitos referem-se à publicação do trabalho em qualquer parte do mundo, incluindo os direitos às renovações, expansões e disseminações da contribuição, bem como outros direitos subsidiários. Todos os trabalhos publicados eletronicamente poderão posteriormente ser publicados em coletâneas impressas sob coordenação da Cognitionis Publishing, da Companhia Brasileira de Produção Científica e seus parceiros autorizados. Os (as) autores (as) preservam os direitos autorais, mas não têm permissão para a publicação da contribuição em outro meio, impresso ou digital, em português ou em tradução. 